\title{
Can Awareness of Actual Risk of Complications Improve Outcomes in Adults with Type 2 Diabetes? Findings of a Pilot Study
}

\author{
Timothy Skinner $^{1^{\star}}$, Melissa Barrett ${ }^{2}$, Charlie Greenfield ${ }^{3}$, Jane Speight ${ }^{4,5,6}$
}

${ }^{1}$ Psychological and Clinical Sciences, Charles Darwin University, Northern Territory, Australia

${ }^{2}$ Hit Nitz 46, Geraldton, Western Australia

${ }^{3}$ Rural Clinical School, Univeristy of Western Australia, Geraldton, Western Australia.

${ }^{4}$ The Australian Centre for Behavioural Research in Diabetes, Diabetes Australia - Vic, Melbourne, Victoria, Australia

${ }^{5}$ Centre for Mental Health and Wellbeing Research, School of Psychology, Deakin University, Burwood, Victoria, Australia

${ }^{6}$ AHP Research, Hornchurch, Essex, UK

"Corresponding author: Timothy Skinner, Professor, Head of Psychological and Clinical Sciences, Charles Darwin University, Ellengowie Drive, Darwin, Northern Territory 090, Australia, Tel: +61 88946 6408; E-mail: Timothy.Skinner@cdu.edu.au

Received date: June 02, 2014, Accepted date: August 18, 2014, Published date: August 21, 2014

Copyright: (c) 2014 Skinner T et al. This is an open-access article distributed under the terms of the Creative Commons Attribution License, which permits unrestricted use, distribution, and reproduction in any medium, provided the original author and source are credited.

\begin{abstract}
56 adults with type 2 diabetes received feedback on their actual risk for five diabetes complications, with half receiving additional goal setting support. Outcome measures were collected at baseline and 9 months. HbA1c and diabetes-related distress both improved, with reductions in distress associated with improvements in glycaemic control $(r=0.33, p=0.014)$.
\end{abstract}

Keywords: Motivation; Type 2 diabetes; Risk reduction; Distress; Risk Information

\section{Introduction}

Despite increasing awareness of diabetes-related complications and availability of effective treatments, a substantial number of people with diabetes have biomedical parameters (hyperlipidaemia, hypertension, and hyperglycaemia) outside the recommended target range [1,2]. One explanation for this may be sub-optimal diabetes self-management $[3,4]$.

Interventions to improve self-care are based typically on the premise that individuals do not take their diabetes seriously enough or that they do not believe themselves to be susceptible. This may be true for some, however, evidence suggests the reverse may be true for many. That is, people overestimate the likelihood that they will develop diabetes-related complications [5-7]. For instance, of adults with an $\mathrm{HbAlc}>64 \mathrm{mmol} / \mathrm{mol}(>8.0 \%), 56 \%$ and $48 \%$ overestimated their risk of myocardial infarction and stroke by more than $20 \%$ [8]. This can lead to a sense of fatalism, resignation and distress. The literature is replete with studies describing these characteristics among people with diabetes $[9,10]$, with recent research showing distress is strongly associated with sub-optimal self-care and metabolic outcomes $[11,12]$.

Our hypothesis was that providing people with accurate information about their risk of developing diabetes-related complications, along with counselling on how they can meaningfully reduce these risks, will encourage people to self-manage their diabetes more effectively and reduce their risks.

\section{Materials and Methods}

Having obtained local research ethics approval, participants were recruited from four general practices in rural Western Australia into a pilot trial, using the following inclusion criteria: adults with type 2 diabetes, aged 40-70 years, an $\mathrm{HbAlc} \geq 64 \mathrm{mmol} / \mathrm{mol}$ ( $\geq 8.0 \%$ ), and one or more additional risks: $\mathrm{BP} \geq 140 / 80$, total cholesterol $>4 \mathrm{mmol} / \mathrm{l}$, or a current smoker. An invitation letter and information sheet were sent to potential participants. General practitioner (GP) records provided medical information needed for the risk profiling. Following collection of baseline data, participants were randomised, using a computergenerated random number. Follow-up data were collected at 9 months.

All participants received an Accu-Chek Mellibase potential risk report (Figure 1) and an explanation during a face-to-face consultation, together with negotiation of options for change culminating in the development of an initial self-management goal [13]. This tool provides personalized risk information for five complications (heart disease, stroke, amputation, retinopathy and kidney failure), and indicates which risk factors have greatest impact on risk reduction. It provides both absolute and relative risk reduction information, and the risk, if treatment targets are achieved. Half the participants also received a follow-up telephone call two weeks later and telephone consultations at 3 and 6 months, with all having a faceto-face consult at 9 months.

\section{Measures and Analysis}

At baseline, all participants completed study questionnaires, providing: basic demographic and medical information; the Centre for Epidemiological Studies Depression scale, a well validated, 20-item, self-report measure of depressive symptomatology [14]; and the Problem Areas in Diabetes scale, a well validated 20-item, self-report measure of diabetes-related distress [15]. Biomedical data were 
Page 2 of 3

obtained from the GP records at baseline, with 9-month data collected by sending out reminders to patients to attend pathology appointments and a final consultation. All pathology testing was conducted by the same laboratory.

All data were analysed using an intention-to-treat analysis, with missing data at 9 months imputed using baseline observation carried forward. Analysis of variance was used to examine between-group and within-group differences. Pearson's correlation was used to examine relationships between changes in $\mathrm{HbAlc}$ and diabetes-related distress.

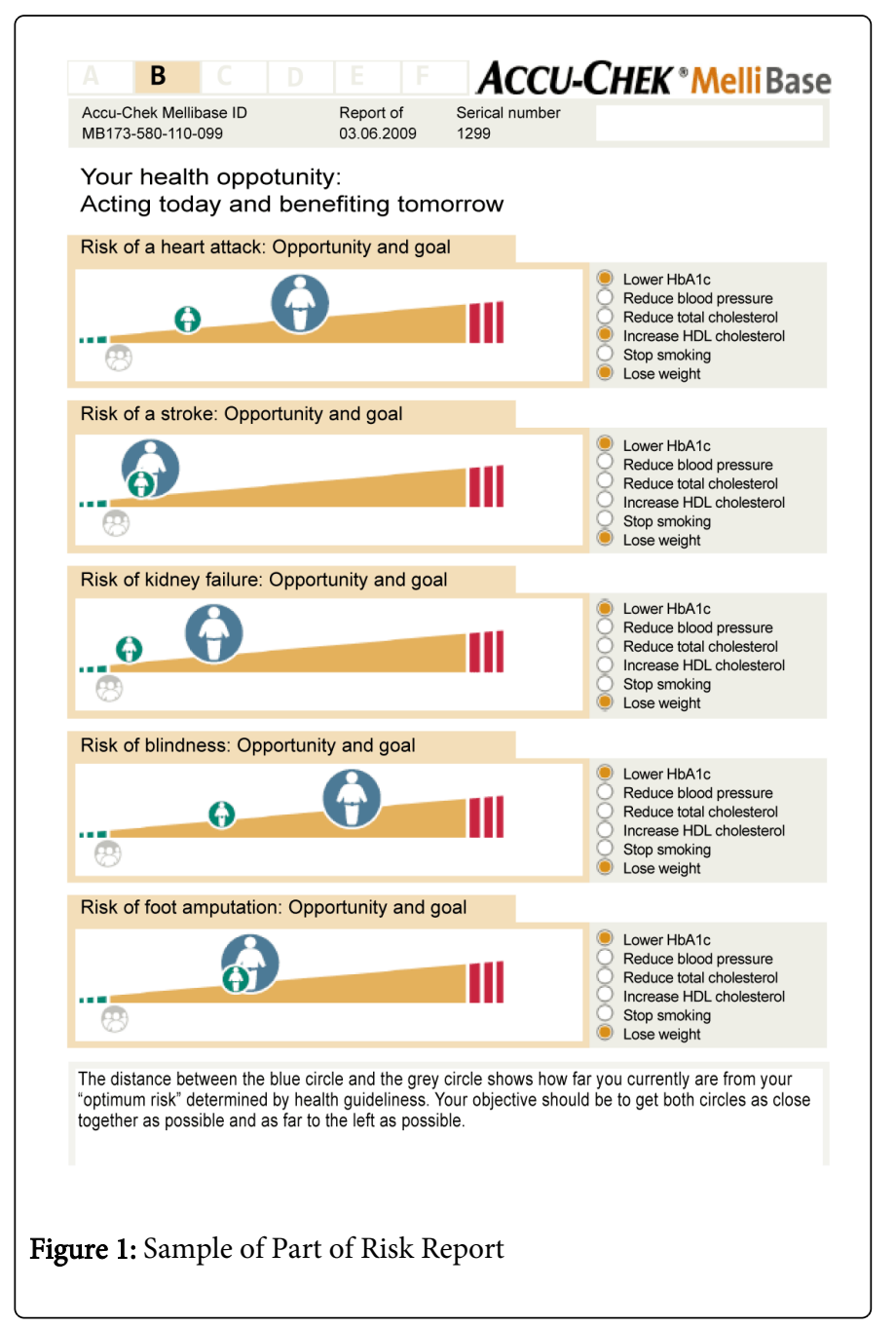

\section{Results}

Fifty-six participants were recruited: 54\% men; mean age 59.3 (SD 11.3 ) years; $54 \%$ had completed only year 10 schooling and $13 \%$ had completed a university degree; $13 \%$ were current smokers. 29 were allocated randomly to receive additional follow-up. There were no statistically significant differences between intervention and control groups at baseline (Table 1).
There was a statistically significant reduction over time in HbAlc $(\mathrm{F}=11.16, \mathrm{df}=1, \mathrm{p}=0.002)$ and diabetes-related distress $(\mathrm{F}=4.24, \mathrm{df}=1$, $\mathrm{p}=0.044$ ) for all participants, with a trend towards a greater reduction in the intervention (Table 1). Overall, there was a trend for a small reduction in body mass index $(\mathrm{F}=3.02, \mathrm{df}=1, \mathrm{p}=0.088)$ but no statistically significant difference between groups. For those with above target lipids (61\%), there was a statistically significant reduction over time $(\mathrm{F}=6.23, \mathrm{df}=1, \mathrm{p}=0.018)$ but no significant difference between groups. For those with established hypertension (38\%), there was no statistically significant effect on systolic or diastolic blood pressure. Greater reductions in diabetes-related distress were associated with greater reductions in $\mathrm{HbAlc}(\mathrm{r}=0.33, \mathrm{p}=0.014)$.

\section{Discussion}

This pilot study sought to explore the feasibility and impact of providing actual, personalised risk profiles and counselling on the metabolic outcomes of adults with type 2 diabetes. Feasibility was clearly demonstrated, with all individuals understanding the risk tool and using the tool to develop specific plans for their diabetes management. The potential impact was also demonstrated, with participation in the study associated with statistically significant reductions in $\mathrm{HbAlc}$ and diabetes distress, and for those above target, in cholesterol, regardless of whether follow-up telephone counselling was provided.

The main issue is whether the significant improvements in HbAlc, cholesterol and diabetes-related distress seen in both groups can be attributed to the provision of the personalised risk information or to common Hawthorne effects. Our feasibility study design does not allow us to answer this question but it does point to the need to conduct a fully powered randomised controlled trial to determine if feedback of actual personalised risk information alone engages people to be more pro-active in managing their diabetes. The correlation between change in $\mathrm{HbAlc}$ and diabetes-related distress is also of note. This supports recent studies indicating that diabetes-related distress is a key potential driver of glycaemic control $[10,11,14]$.

\section{Conclusions}

Our primary aim was to test the feasibility of providing adults with type 2 diabetes with accurate personalised information about their risk of developing diabetes-related complications. This was, indeed, feasible, did not increase diabetes-related distress, and is likely to be viable for delivery within routine primary care. Our data suggest that a full randomised trial is warranted to determine the impact of actual personalised risk information on diabetes outcomes.

\section{Declaration of Competing Interests}

Roche Diagnostics provided the researchers with access to the Accu-Chek Mellibase ${ }^{\infty}$ risk engine free of charge. It was not involved in the study design, analysis, interpretation or writing up. The authors have no other competing interests to declare.

\begin{tabular}{|l|l|l|l|l|l|l|}
\hline & \multicolumn{2}{|l|}{ Intervention Group } & \multicolumn{2}{l|}{ Control Group } & $\begin{array}{l}P \\
\text { time 1-time 2 }\end{array}$ & $\begin{array}{l}p- \\
\text { group by time }\end{array}$ \\
\hline & Baseline & 9 months & Baseline & 9 months & & \\
\hline
\end{tabular}


Citation: Skinner T, Speight J, Barrett M, Greenfield C (2014) Can Awareness of Actual Risk of Complications Improve Outcomes in Adults with Type 2 Diabetes? Findings of a Pilot Study. J Nurs Care 3: 191. doi:10.4172/2167-1168.1000191

Page 3 of 3

\begin{tabular}{|c|c|c|c|c|c|c|}
\hline HbA1c: $\mathrm{mmol} / \mathrm{mol}$ & $73.0(12.0)$ & $69.0(16.4)$ & $75.0(9.8)$ & $68.0(16.4)$ & .002 & .490 \\
\hline HbA1c: \% & $8.8(1.1)$ & $8.5(1.5)$ & $9.0(0.9)$ & $8.4(1.5)$ & .002 & .490 \\
\hline BMI & $33.5(5.2)$ & $33.0(5.1)$ & $34.0(5.7)$ & $33.8(5.4)$ & .088 & .437 \\
\hline Systolic BP & $134.7(19.5)$ & $137.0(22.0)$ & $135.6(20.0)$ & $137.0(20.0)$ & .479 & .766 \\
\hline Diastolic BP & $76.8(9.1)$ & $75.0(14.0)$ & $78.6(12.3)$ & $80.0(13.0)$ & .957 & .186 \\
\hline Total cholesterol & $4.7(1.3)$ & $4.5(1.2)$ & $4.2(0.9)$ & $4.0(1.0)$ & .222 & .957 \\
\hline HDL cholesterol & $1.2(0.4)$ & $1.2(0.5)$ & $1.0(0.2)$ & $1.1(0.3)$ & .239 & .671 \\
\hline LDL cholesterol & $2.5(0.8)$ & $2.7(1.0)$ & $2.3(0.7)$ & $2.1(0.7)$ & .567 & .292 \\
\hline Depression (CES-D) & $18(15)$ & $15(15)$ & $9(11)$ & $10(12)$ & .441 & .228 \\
\hline $\begin{array}{l}\text { Diabetes-related } \\
\text { (PAID) }\end{array}$ & $21(16)$ & $17(13)$ & $14(10)$ & $14(11)$ & .044 & .090 \\
\hline
\end{tabular}

Table 1: Comparison of study outcome measures (Mean and SD) between intervention and control groups at baseline and 9-month follow-up.

$P$ value for main effect of time for both groups

$\mathrm{P}$ value for group by time interaction effect

\section{References}

1. Ackermann RT, Thompson TJ, Selby JV, Safford MM, Stevens M, et al. (2006) Is the number of documented diabetes process-of-care indicators associated with cardiometabolic risk factor levels, patient satisfaction, or self-rated quality of diabetes care? The Translating Research into Action for Diabetes (TRIAD) study. Diabetes Care 29: 2108-2113.

2. NADC, 2007, "Final Report ANDIAB 2006: Australian National Diabetes Information Audit and Benchmarking", Australian Government Department of Health and Ageing, Canberra.

3. Donnan PT, MacDonald TM, Morris AD (2002) Adherence to prescribed oral hypoglycaemic medication in a population of patients with Type 2 diabetes: a retrospective cohort study. Diabet Med 19: 279-284.

4. Toobert DJ, Hampson SE, Glasgow RE (2000) The summary of diabetes self-care activities measure: results from 7 studies and a revised scale. Diabetes Care 23: 943-950.

5. Frijling BD, Lobo CM, Keus IM, Jenks KM, Akkermans RP, et al. (2004) Perceptions of cardiovascular risk among patients with hypertension or diabetes. Patient Educ Couns 52: 47-53.

6. Asimakopoulou KG, Skinner TC, Fox C, Spimpolo J, Marsh S. Unreaistic pessimism about risk of Coronary Heart Disease and stroke in patients with type 2 diabetes. Patient Education Counselling. 2008;71(1):95-10111

7. Asimakopoulou KG, Fox C, Spimpolo J, Marsh S, Skinner TC (2008) The impact of different time frames of risk communication on Type 2 diabetes patients' understanding and memory for risk of coronary heart disease and stroke. Diabet Med 25: 811-817.
8. Gonzalez JS, Fisher L, Polonsky WH (2011) Depression in diabetes: have we been missing something important? Diabetes Care 34: 236-239.

9. Pouwer F, Skinner TC, Pibernik-Okanovic M, Beekman ATF, Cradock S, Szabo S, et al. (2005) Serious diabetes-specific emotional problems and depression in a Croatian-Dutch-English Survey from the European Depression in Diabetes [EDID] Research Consortium. Diabetes Research and Clinical Practice 70:166-173.

10. Fisher L, Hessler DM, Polonsky WH, Mullan J (2012) When is diabetes distress clinically meaningful?: establishing cut points for the Diabetes Distress Scale. Diabetes Care 35: 259-264.

11. Fisher L, Mullan JT, Arean P, Glasgow RE, Hessler D, et al. (2010) Diabetes distress but not clinical depression or depressive symptoms is associated with glycemic control in both cross-sectional and longitudinal analyses. Diabetes Care 33: 23-28.

12. Edwards A, Unigwe S, Elwyn G, Hood K (2003) Effects of communicating individual risks in screening programmes: Cochrane systematic review. BMJ 327: 703-709.

13. Grover SA, Lowensteyn I, Joseph L, Kaouache M, Marchand S, et al. (2007) Patient knowledge of coronary risk profile improves the effectiveness of dyslipidemia therapy: the CHECK-UP study: a randomized controlled trial. Arch Intern Med 167: 2296-2303.

14. Beekman AT, van Limbeek J, Deeg DJ, Braam AW, de Vries MZ, et al. (1997) Criterion validity of the Center for Epidemiologic Studies Depression scale [CED-D]: results from a community-based sample of older subjects in The Netherlands. Psychological Medicine. 27:231-5

15. Snoek FJ, Pouwer F, Welch GW, Polonsky WH (2000) Diabetes-related emotional distress in Dutch and U.S. diabetic patients: cross-cultural validity of the problem areas in diabetes scale. Diabetes Care 23: 1305-1309. 